WellBeing International

WBI Studies Repository

$5-2012$

\title{
Attitudes of Canadian Beef Producers Toward Animal Welfare
}

\author{
J. M. Spooner \\ University of British Columbia \\ C. A. Schuppli \\ University of British Columbia \\ D. Fraser \\ University of British Columbia
}

Follow this and additional works at: https://www.wellbeingintlstudiesrepository.org/farawel

Part of the Agribusiness Commons, Animal Studies Commons, and the Business Law, Public Responsibility, and Ethics Commons

\section{Recommended Citation}

Spooner, J. M., Schuppli, C. A., \& Fraser, D. (2012). Attitudes of Canadian beef producers toward animal welfare. Animal Welfare, 21(2), 273-283.

This material is brought to you for free and open access by WellBeing International. It has been accepted for inclusion by an authorized administrator of the WBI Studies Repository. For more information, please contact wbisr-info@wellbeingintl.org.

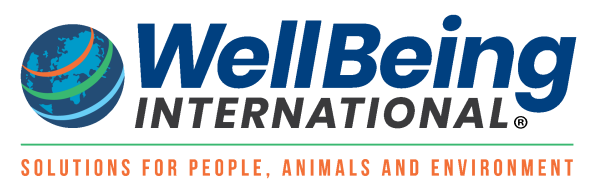




\title{
Attitudes of Canadian Beef Producers Toward Animal Welfare
}

\author{
J.M. Spooner, C.A. Schuppli, and D. Fraser \\ University of British Columbia
}

\author{
KEYWORDS \\ animal welfare, attitudes, beef, Canada, qualitative, values
}

\begin{abstract}
Commercial beef production in western Canada involves raising cows and calves on large tracts of grassland, plus grain-based 'finishing' of animals in outdoor feedlots. This study used open-ended, semi-structured interviews to explore views on animal welfare of 23 commercial beef producers in this system. Although wary of the term 'animal welfare', participants understood the concept to encompass three well-known elements: (i) basic animal health and body condition; (ii) affective states (comfort, contentment, freedom from hunger or thirst); and (iii) the ability to live a 'natural' life. Participants attached importance to protecting animals from natural hardships (extreme weather, predators), yet many regarded some degree of natural challenge as acceptable or even positive. Quiet rumination was uniformly regarded as indicating contentment. Avoiding 'stress' was seen as a central goal, to be achieved especially by skilful handling and good facilities. Invasive procedures (branding, castration, de-horning) were recognised as painful but were accepted because they were seen as: (i) necessary for regulatory or management reasons; (ii) satisfactory trade-offs to prevent worse welfare problems such as aggression; or (iii) sufficiently short-term to be relatively unimportant. Other issues including poor facilities, rough or excessive handling, poor nutrition, and failure to protect health - were regarded as more serious welfare concerns. While feeling constrained by low profits, participants saw good welfare as crucial to profitability. Participants uniformly expressed an ethic of care, enjoyment of working with animals, and varying degrees of willingness to sacrifice personal comfort for animal well-being. We argue that animal welfare policy and advocacy are likely to be more successful in engaging producers if they acknowledge and address producers' views on animal welfare.
\end{abstract}

\section{Introduction}

The welfare of food-producing animals has become the focus of intense public debate among philosophers, social critics and animal advocates, but the views of animal producers, who have direct experiential knowledge of food animals, have played remarkably little role in the public debate. Recent research has characterised the views of some European producers, often finding that producers differ substantially from other citizens in what they consider important for animal welfare. Whereas consumers 
generally stress the 'naturalness' of animals' living conditions (te Velde et al 2002; Lassen et al 2006; Vanhonacker et al 2008; Ellis et al 2009) animal producers tend to stress basic health (te Velde et al 2002; Bock \& van Huik 2007; Vanhonacker et al 2008). Of the few inquiries that have focused specifically on beef cattle producers, most have also been based in Europe (eg Wilkie 2005; Boivin et al 2007; Kjaernes et al 2008). In Canada's western provinces, where beef production involves a distinctive system involving year-round 'cow-calf' production on extensive rangeland combined with grain-based 'finishing' in outdoor feedlots, it seems likely that producers might also hold distinctive views on animal welfare. Our method was to interview beef producers directly about their conceptual and operational definitions of 'animal welfare'. We hoped to achieve a realistic and nuanced picture of their attitudes, values, and beliefs regarding good or satisfactory lives for animals. We also hoped to provide policy-makers with a fundamental understanding of beef producer attitudes so as both to inform the public debate and provide constructive input into animal welfare policy. This paper reflects findings from the first of four interview studies undertaken with members of the Canadian beef, pig, dairy and consumer sectors.

\section{Materials and methods}

Interviews were conducted with 23 individuals directly involved in the rearing and handling of beef cattle in western Canada. Participants were recruited by a purposive sampling strategy designed to include producers engaged in ranching and feedlot operations in all four western provinces of Canada. Prospective participants were identified by several 'key informants' (Hammersley \& Atkinson 2007) knowledgeable about the industry, and through provincial farm animal care associations, members of the University of British Columbia Animal Welfare Program, and directly by the researchers. Because no major differences in views were observed between cow-calf ranchers and feedlot operators, the two groups were termed collectively 'beef producers' in the analysis.

\section{Participant information}

The 23 participants included 1 to 8 from each of British Columbia, Alberta, Saskatchewan and Manitoba. Seventeen were cow-calf ranchers, operating ranches with breeding females and producing young animals to be finished by feedlots or in one case by themselves. One participant was recently retired, two described their operations as organic, and one described her operation as certified by the Society for the Prevention of Cruelty to Animals. Five other participants managed or owned feedlots (where cattle are confined outdoors and fed high-energy rations until slaughter) and one managed a conglomerate of cowcalf producers. The number of cattle under the care of the participants ranged from 75 to 7,400 cows among cow-calf ranchers (mean of 1,018) and 7,000 to 24,000 among feedlot operators (mean of $11,375)$. In 22 of the 23 cases, participants were at least second-generation producers. All but one participant raised or managed cattle on a full-time basis.

\section{Interviews}

Interviews, which lasted 1 to $2 \mathrm{~h}$, were conducted 'face-to-face' (20), by telephone (2), or by a combination of face-to-face and telephone (1). Immediately before each interview, participants were given a verbal summary of the study and were asked to review and sign a consent form, approved by the University of British Columbia Research Ethics Board, stressing confidentiality and the right to withdraw from the study at their discretion, although none withdrew. Participants were invited to respond to an open-ended, semi-structured interview schedule that had been pilot-tested by three student volunteers involved in farm animal welfare and production. Initial questions covered demographic details, current farm animal operations, personal ranching/production histories, and whether participants ate meat (which all did). All subsequent questions sought the meaning of animal welfare in various ways. Respondents were encouraged to relate what 'farm animal welfare' meant to them including any views on animal 
welfare beyond those specifically involving beef production. Participants were also asked to describe the criteria they might use to assess the welfare of a neighbouring animal production operation similar to their own. At this point, participants were invited to respond to one of three additional textual queries. The first five participants were presented with a brief 'questerview' (a research tool in which a self-completed questionnaire is administered within a qualitative interview; see Adamson et al 2004) intended to further elucidate views on farm animal welfare. The remainder received either: (i) a compilation of 30 welfarerelated attributes reflecting the three elements of animal welfare (basic health and functioning, natural living, and affective states as described by Fraser et al 1997) (seven participants); (ii) a compilation of commonly cited welfare-related practices specifically relevant to beef production (comprising de-horning, branding, castration, forced weaning, unattended calving, stockperson handling, injection of hormones, exposure to severe weather/possible temperature stress, the ready availability of quality water, and stocking density practices in feedlots) (four participants); or a combination of both (seven participants). Participants were invited to address any or all items in the compilations in light of their earlier comments about animal welfare. Participants were subsequently asked: (i) whether they had ever encountered views about welfare that differed from their own; (ii) about their ideas regarding the emotional capabilities of their animals (and the extent to which they may endeavour to accommodate animal emotions); (iii) about any animal welfare-related changes they may have introduced into their operations over their careers; and (iv) about the general nature of the relationship between producers and their animals. In closing, some were also asked whether they would continue ranching in the event of a major financial windfall, and if so, about any changes they might make in their operation with regard to animal welfare. Most respondents answered all questions, usually in the same order. Finally, participants were invited to make any additional comments relevant to animal welfare, and all were invited to contact the researchers to add any supplementary comments afterwards, although no follow-ups were received. All interviews were tape-recorded and transcribed (verbatim) and participants were offered a copy of the transcript if desired (no requests). Numbers were assigned to each participant and appear with each quotation.

\section{Results}

Animal welfare

When participants were asked to provide their definition of 'animal welfare', most reported that they themselves never used the term. For example, a study participant randomly designated by the research team as number ' 150 ' stated:

150: "It's a term that I don't hear in the rural community... If I've got a group of neighbours helping us with the cattle, nobody talks about animal welfare".

In fact, some participants linked 'animal welfare' to concerns raised by those outside the industry to criticize production practices:

262: "When that term is mentioned in media or whatever, it almost always seems to be linked to something negative.... When we start talking about 'animal welfare' to our city cousins, I'm afraid that they're thinking that it's an investigation of something that's gone wrong...".

\section{Welfare as 'comfort' or 'contentment'}

Instead of 'welfare', participants decidedly favoured the terms 'comfort' or 'contentment', which they treated roughly as equivalent to welfare:

142: "I think contentment would be a better term for animals... The most you can hope for is a contented animal". 
140: “...the basics of animal welfare are that you are handling, managing and treating your animals to the best of your ability, for their personal comfort... Give them every opportunity to be comfortable".

118: "To me it means are you doing everything you possibly can to make life as comfortable and meaningful to the animals that you're in charge of".

Participants were certain that they could assess visually the comfort and contentment of their cattle:

262: "Comfortable we definitely can see, and people that are around livestock all the time will know in body language and the way cattle or livestock are acting, as to whether they're comfortable".

182: "If they're not content, it's simple for me to tell. I can tell if an animal's sick or has a temperature-just by looking".

During free exchanges regarding good lives for their own cattle, many participants volunteered the term 'happy animals'. In most cases, 'happy' was clearly intended to serve as a synonym for 'comfortable' or 'contented'. On occasion, it was used to refer to cattle showing play-like behaviour. However, when asked, other participants were adamant that animal 'happiness' was not a term they would use:

262: "Happy is a term that I don't know if I'd want to use, because I don't know if animals get happy. I couldn't answer that. But, comfortable we definitely can see...”.

References to 'contented' or 'happy' animals were frequently used in the context of rumination:

120: "Well, the first thing you look at... when you're eyeballing for herd health is that they're relaxed and chewing their cud, and that's an indication of being happy".

182: "A cow that's content is laying [sic] there and just chewing her cud and is absolutely, probably, maybe not thinking about anything! That's content!... I honestly think if you measured their brainwaves, there would be nothing there... we spend a lot of money to meditate and do yoga and to try to get to the state that the ruminating cow is already at".

Welfare as natural living

Participants also insisted that a good life for beef cattle requires the opportunity to live in a natural manner:

144: "I have a true belief that animals must be able to exhibit their natural behaviours, whatever that is. Pigs root, chickens scratch, cattle graze, sheep browse - right...? none of them were meant to be in barns".

Supporting this view, one feedlot operator added:

110: "If the cattle are on concrete for too long they typically don't eat as much and they just kind of - they'll slowly go off feed a little bit... but if they're in pens that have dirt where they can roam around... and dig a little bit and do whatever, they just seem to be a little happier.... Cattles' natural environment is outside and they seem to be the happiest there...".

Nonetheless, participants acknowledged that nature can be harsh. Animals reared extensively are subjected commonly to predation, injuries, harsh weather, and unattended calvings. And, while such 
adversities were undeniably recognised as potential threats to cattle, exposing one's animals to them was not regarded as negligent:

182: "The livestock here are extremely well taken care of. They live a contented life, for the most part. There could be weather, there could be whatever, but I mean, that's nature. Nature's not pretty necessarily...".

120: "Some injuries are part of natural living. Bulls break their penises... cows get the odd broken leg".

144: "Variable weather conditions: I think that that is a part of humane animal welfare... they get to experience variable weather conditions".

However, participants pointed out various ways in which they sought to offset or prevent natural hardships. Participants cited providing dry bedding during wet weather, safety from persistent predation, regular access to feed, prevention and treatment of disease, and enhanced genetics in order to lessen complications at birth and thereafter:

116: "Animals that are in the wild suffer more pain than... the animals that I look after, because we have a certain amount of supervision over some of the hazards that a wild animal doesn't have... Starvation for deer is something that we go through here in a severe winter, and all natural animals go through that, where myself, that's something that we prevent".

126: "That beautiful picture of cows all roaming out... isn't really true... That storm that we had here 10 days ago - if the farmer wasn't there looking after those cattle, we'd have massive death loss".

182: "[If] we pull the fences and turn these cattle loose they're going to meet an uglier death than they're going to now. A lot of them are".

120: "When we buy bulls, we focus on a multitude of things and the first one is easy calving... [Our manager] is... very careful about what he chooses for bulls, so that we don't have calving difficulties. Because how much do your cows weigh? Twelve hundred pounds? They're not very big cows. So we don't buy great big huge bulls, right?"

\section{Welfare as basic health and growth}

Producers also stressed the importance of animal health, frequently referring to the 'body condition' of an animal as the most reliable indicator of physical well-being:

112: "Oh, condition, condition. You can see that. Condition of the animal... for me, hair coat is a big indication of an animal's... health and situation".

140: "And certainly the body condition factor with the cows is very important. A healthy cow in good condition is going to drop a healthy calf $99 \%$ of the time and is going to be able to take care of that calf properly. So, I put huge emphasis on cattle condition".

One producer linked body condition to 'emotional needs':

126: "I don't know what the emotional needs really are, but if the body condition is good and they look good and they're healthy, does that go along with emotional needs? I would suggest yeah". 


\section{Welfare and steady weight gain}

Participants placed pre-eminent importance on the link between 'comfortable' animals and steady, daily growth. A healthy animal, ruminating contentedly and gaining weight at a steady pace, was seen as eventually remunerative. As a result, many participants recited the phrase, "If we look after our animals, they will look after us". Other perspectives included:

110: "Basically to me, 'farm animal welfare' is the idea of doing what's best for the animal... and I guess the economics go along with that as well... If an animal is well fed and healthy, it's going to remain happy and productive".

146: "Bottom line: if there's no welfare you don't make any money because if you don't have the good welfare we're not getting the gains out of the cattle".

260: "We look after our animals because we like them and we want to do it properly, but when it comes right down to it, if you don't, then it's your loss".

\section{Stress}

The antithesis of good welfare and steady weight gain was seen as anything that interrupted or impeded the growth process or resulted in weight loss. The term most frequently used for such impediments was 'stress'. Some participants used 'stress' specifically for failures to accommodate the biological needs of an animal by failing to provide feed, water or protection:

144: "Well, a happy animal is an animal that... is not stressed by a limited essential resource, such as food or water... is given all the abilities to maintain health..... They are not unduly subjected to the stress of parasites and they are not subjected to stress of movement".

Others used the term to refer to the emotional state of animals facing adversity:

254: "The number one thing is quiet and calm.... [since] stress on an animal is huge.... So, I mean, we do the best we can to keep that stress to a minimum in our operations".

Stress in a maturing beef animal is believed to impede its steady rate of growth. As a result, stress collectively entails a 'lose-lose-lose' scenario: loss to the animals, to the rancher and ultimately to the industry as a whole. Producers, therefore, emphasised the need to reduce or minimise stress where possible:

140: "Today, everything you do with an animal is related to how you're going to stress that animal, and you can relate that to how many dollars you're going to end up getting .... A stressed animal is not growing. If you want to look at the total logic of it, a stressed animal is not making you money".

Stressors were generally grouped into two categories: avoidable stressors such as poor handling, and unavoidable stressors that are required in the contemporary rearing of beef cattle.

\section{Avoidable stress}

Many participants indicated that they adopted 'low-stress handling', commonly citing well-known advocates such as 'Bud' Williams (Williams 2011): 
248: “...A guy called Bud Williams... gave lots of talks on it and how the cattle can be actually moved much easier and more efficiently with certain techniques, and it also improves their health. And I think that's caught on a lot...".

144: "The policy is that every person that handles animals here [on-farm] takes a low-stress cattle handling clinic, approved by the management of the farm".

Other participants emphasised well-designed handling equipment:

172: "You can have the best people in the world, but if you've got a really badly designed system it's going to be stressful on cattle and it's going to be stressful on the people. If you've got a good system, even with people that are not so well trained, it's still workable".

Hence, participants widely maintained that knowledge and use of low-stress handling methods represented a way to minimise avoidable stress.

\section{Unavoidable stress}

Participants also saw certain stressors as unavoidable and often routine. In the vast majority of cases, producers described actions such as castration, branding and dehorning as regrettable but unavoidable. Most of these practices were seen as necessary to meet regulatory requirements or management and safety concerns. For example, hot-iron branding - the traditional practice used to identify animals — was acknowledged as painful, but necessary for regulatory purposes:

134: "We... brand our cows... for identification reasons. And we don't like the idea of branding".

140: "Branding is an issue that the public sees as hurting to an animal, which I agree, it is. It hurts".

Some participants spoke of ways to reduce the stress of branding by using cold-temperature 'freeze' branding, and to reduce the pain of castration by using tight rubber rings ('elastrators') rather than surgical castration:

168: "The old argument though comes to how to actually castrate them: the elastrator seems to be the one that's the least painful, I would think".

Others who favoured surgical castration, nonetheless acknowledged the disagreeable elements involved:

254: "Straight castration, to me, is the only way to go... but... it's a hard one to defend, because it is one of those things. But you can't get away from castration. You can't put a big herd out with bull calves".

De-horning (removal of horns or horn buds of young cattle) was seen as necessary to prevent injury to human handlers and other animals:

168: "And the horns, they're not useful for anything other than gouging another animal or killing the person who's handling them... I would never want to put... our cattle out with an animal with horns".

Again, some participants emphasised better handling to reduce stress associated with the procedure:

254: "The big thing is... to get them in the chute, you nip their horns and you let them out. You don't let them stress and strain". 
Similarly, vaccinations were seen as stressful but necessary for animal health:

260: "There's a lot of people that don't like to put their own child through the pain of having a vaccination, and yet we do it.... It is stressful for them, for sure".

Again, the emphasis was placed on reducing stress as much as possible:

248: "If necessary, they've got to be given their vaccinations, de-horned, castrated, but in as least stressful way as possible, I guess".

Forced weaning of calves from their dams was also recognized as stressful but necessary:

254: "I mean, it's a hell of a thing, the weaning process!.... you take a calf away from a cow, they're having to go on their own, where they've had this mum beside them for the last six or seven months. It's a hell of an adjustment for them".

Other participants noted that castration is needed to avoid other animal welfare problems including 'riding' (sexual mounting) of other animals and out-of-season calving:

184: "Why do you castrate?... to me it's more inhumane to have all them bull calves riding each other".

140: "They can't stay with a herd as bulls. Safety, mismanagement, the breeding practices, heifers, it just-it cannot happen. So, castration is an absolutely necessary management tool".

Different views or reactions to pain

There was agreement among participants that invasive procedures invariably cause some pain or stress, yet participants differed in the level of importance they attached to the issue. Some participants placed emphasis on minimising pain as much as possible:

182: "We have a really good crew — very quick. Most calves are down less than a minute... it's really important to me and my family. What's in it for us to hurt them any more than necessary? It's an awful thing PR [public relations]-wise for the beef industry, but I don't know how you get around it... I mean, if you give me a better way, I'll do it".

Other participants tended to downplay if not dismiss the importance of pain from invasive procedures with phrases like, "It doesn't hurt for long", or "We can see that it didn't hurt much because everything is fine again", or "Do it young and they don't even remember". Others considered that the stress associated with the restraint involved was more significant than the pain caused by the procedure:

156: "We, um, generally ring our calves young... they bawl for about two seconds... because you've got a hold of them, and they're scared. And then after that, they're fine".

None of the participants reported using pain medications for invasive procedures. Some implied that restraining the animal for the time required for local anaesthetic to take effect is stressful for the animals, and at least one objected to the use of anaesthetics on the basis of the drug itself causing pain:

168: "We've talked to [our vet] about using anaesthetic. He suggests no, because anaesthetic burns. It's a very sensitive burning when it goes in. And he says it's not highly recommended, especially when you're doing young stock ...". 
Welfare concerns raised by participants

When asked to identify their own concerns regarding animal welfare, participants alluded to various practices that they saw as avoidable and hence as objectionable for both animal care and economic reasons. In seemingly ascending order of importance, these were: (i) failure to upgrade potentially poor handling facilities such as slippery floors; (ii) over-stocking of pens in feedlots; (iii) hasty or arbitrary use of electrical cow prods to load or move animals; (iv) failure to provide suitable shelter or windbreaks during harsh weather; $(v)$ failure to maintain good health through vaccination and prompt treatment of illness or injury; (vi) failure to provide adequate nutrition throughout the year and/or sufficient fresh water in summer; (vii) rough handling ('cowboying') or harassment; and (viii) allowing unskilled people to conduct invasive management procedures such as castration.

There were also major concerns about small-scale, part-time producers whom participants referred to as 'hobby farmers':

168: "There are a lot of people out there that think they can... turn a quick buck, or [reduce] their farm taxes by having a handful of animals.... And they don't have the time, or the knowledge, or the want-to to ask for help. And you see an awful lot of animals that are abused or not treated fairly".

Participants cited a lack of knowledge among 'hobby farmers' as a common cause of animal welfare problems, alleging that more than half of the complaints received by the industry were related to hobbyists:

254: "Where we've found the bulk of the problem - and maybe where some of the issues come is - people don't know what the hell they're doing. You get a lot of your-and I don't mean to knock them—but a lot of your smaller [operators] that have just a handful [of animals]".

One participant claimed that hobby farmers lack confidence in handling animals: "They're scared to dehorn them, they're scared to do this, they're scared to do that, and they don't do the job properly". Another complained about lack of commitment by small-scale producers who "don't attend meetings and who don't read". Another alleged that part-time producers would leave animals unattended for unacceptably long periods while pursuing off-farm activities. Finally, hobbyists were also accused of practicing what some considered among the worst type of animal abuse possible - namely, keeping animals in isolated pens and thus failing to accommodate basic social and behavioural needs - a concern that participants extended beyond cattle to include individually penned horses and even house-bound dogs.

Some participants also expressed dissatisfaction with inadequate levels of animal care provided by neighbouring commercial producers, and there was universal concern about 'wrecks' - ranch operations that failed to provide even minimal animal care likely because of personal or family difficulties.

\section{Controversies}

The interviews also identified areas of disagreement among producers. Participants disagreed about the appropriate age and methods of castration and de-horning. Some participants were very critical of those who delayed the de-horning of calves:

150: "If it's not done young, the de-horning, then it's a terrible job".

And also of delaying castration until late autumn: 
134: "Years ago... somebody persuaded us that we should wait [before castrating] and we'd get better growth.... It was late fall. That was not a good day. It wasn't a good scene. But there's people that do [that] all the time".

Moreover, annual calving dates varied considerably among ranches, ranging from January (winter) through May (spring). In almost all cases, non-organic ranchers - regardless of their own calving season - did not voice welfare-related concerns about winter calving. Organic participants, however, plus one non-organic producer, emphasised the welfare and management-related benefits of spring calving. One noted that calving in May occurs when, "the weather is warm, so it's a lot more conducive to animals that are born with a summer coat", and that predators such as coyotes have abundant food from small mammals and are less likely to attack calves. This participant noted: "The only reason that cows calve in January, is because economically... you want the largest possible calf within that year. And the best way to do that is to have them born December 31st. But usually it's twenty-five or thirty below with a howling wind and a snowdrift...". Another claimed that the process of parturition is easier in the spring:

156: “... cows have way less trouble calving when the weather's nice... they're moving around so their muscles are working. They're not putting all their energy into huddling and being warm, so they're loose".

In addition to differences in views about parturition, organic and non-organic producers were critical at times of alleged practices of the other. One non-organic producer considered that organic regulations have the potential to foster poor animal welfare:

260: "When we have a sick animal, we give it an injection. We give it penicillin or some other form of antibiotic. We treat it. If you're in the organic business, if your animal's sick and you treat it, you have to pull it out of the organic stream".

However, organic producers reported that they would not withhold antibiotics from sick animals even if this required that the animals be marketed as non-organic. One noted that because they cannot vaccinate cattle, they are especially motivated to reduce stress in animals in order to prevent disease.

For all producers, differences also surfaced on how long (if at all) cattle should be 'finished' on a grainbased diet. According to one cow-calf producer:

182: "They push cattle to extremes in feedlots that they were never designed to do. A ruminant wasn't designed to eat grain".

Cattle auctions, where animals are bought and sold, also proved controversial. One participant complained:

150: "The system we have of the auction markets is... a terribly inefficient system. It causes tremendous stress".

One participant expressed enthusiasm for the growing movement toward computer-mediated sales to avoid the use of auction markets. Another claimed that the stress of handling and detaining animals at auction markets is a common cause of disease.

However, another participant saw progress at auctions:

248: "I think the auction yards are getting better. At one time, I mean, they just didn't care. They'd have their little old whips and want to move them through as quick as possible and things like 
that. But, you know, the industry's putting pressure on the auction yards to have their employees somewhat experienced with low-stress handling".

There also appeared to be personal differences over appropriate levels of care, especially among cowcalf producers, and over how much self-sacrifice is appropriate for the sake of one's cattle. One participant made reference to 'spoiling' animals, comparing excessive attention to cattle with 'using six coats of paint' where two would suffice. In contrast, other producers had opted to completely eliminate electric stock prods, while one used a topical cream to facilitate healing and lessen pain in hot-iron branding. One participant attached great importance to checking animals every two hours during nights in calving season in order to prevent animal suffering:

112: “... what if that cow has a problem? She lays [sic] there all damned night with a backwards calf or a calf with a foot back. So it's not the point that you lost the calf. It's not the point that maybe you've got a downer cow for a week. The point is, that animal suffered all bloody night because of your management practices. I can't justify that".

Others acknowledged limits on their degree of attention:

128: "I love calving season. I love the baby calves. You know, we work our butt off so that they don't freeze when it's thirty below. But there are also times when we're both exhausted, falling into bed at eleven, that neither one of us can get up at three".

Finally, there were controversies over the circumstances that require veterinary interventions, with one producer accusing others of saving money by foregoing veterinarian visits altogether.

Economic constraints

Although good welfare was seen as necessary for productivity, economic constraints were also recognised. Some participants emphasised that very slim profit margins constrained their ability to provide amenities for their animals:

110: "... if you could make more money raising cattle, the potential would be there to maybe go out in your pens and build the odd little shelter for them in the event of a storm ...just to put your mind at ease that your cattle are a little bit happier. But the reality is that the economics aren't there and so you have to just do the best with what you have".

Participants were unanimous in emphasising that market and other financial forces had important effects on beef production practices and the industry in general:

110: "Agriculture producers in this country have had very slim margins since the early $80 \mathrm{~s}$, so we're going on close to thirty years now and there's getting to be fewer and fewer producers out there because I think the majority of them won't compromise animal welfare just to try to get a breakeven out of it, so they're getting right out of the industry".

At the same time, producers stressed that economic challenges did not undermine animal welfare:

248: "We'd try to do everything as efficiently as possible and... properly handled cattle will reward you as much as anything will. There is no way that we can try and squeeze a few extra dollars out... of the animals, by shortening them on feed or anything like that, or rushing them through to somewhere". 
128: "We're not going to abuse our animals because financially it doesn't make sense either... this is our livelihood, and our bottom line falls if we were not taking care of these animals".

140: "I have relied on my veterinarian to give me a herd health-care programme that is protecting my herd. But in doing that, it's protecting my bottom line. So, it may be a little selfish in a way in that I'm protecting my livelihood by keeping my animals healthy. It also is an animal welfare benefit because healthy animals are happy animals".

168: "Why would you mistreat your animal... why do that to one of your own assets in your business?"

Whereas participants equated animal welfare with low stress, contentment, steady gains and good health that would improve production, they saw consumer concerns over animal welfare as relating to issues that would increase costs. Nonetheless, they were willing to incur such costs as long as consumers paid. According to one feedlot operator, he was willing to provide 'grass-fed finished, non-hormonal or traceable product' if desired:

110: “...if people are willing to pay more for that stuff, you know, power to them. That's great”.

126: "So we'll do whatever they want us to do, but they got to pay for it. And if it's profitable to do it, l'll do it, as long as l'm not abusing the animals...".

130: "...if people want to buy it, well, why not go for it? You know, hey, if people will pay a premium, if the public says, 'This is what we want', then pony up...".

Concern over external pressures

At times, participants were critical of what they regarded as unfounded or mis-directed public concerns regarding animal welfare. One participant blamed criticism of ranching practices on "too much humanizing of animals and using human values when addressing issues for animals", noting that:

260: “... some animals are actually better, especially in our environment, to be outside, rather than being stuck in a barn or in a sheltered place all winter where they could be confined, or in a place where it might end up being damp. And, yet that might look better or it might make people feel better, but that's not necessarily the right thing for the animals".

Another agreed:

182: “...people would think cattle standing here in a howling blizzard are probably in a great deal of discomfort. But generally, they're ... okay. They don't want to come in the house".

In some cases, laws motivated by animal welfare concerns were viewed as actually contrary to animal welfare. In particular, regulations requiring cattle to be unloaded and rested during long journeys were widely seen as bad for the animals:

130: "...the stress of unloading, being offered rest time and then coming back on [the truck], I really have to ask is that more stressful than just the extra hour or two or three or four?"

260: “...there's no doubt, it is stressful getting the animals onto the truck, but it isn't serving any good purpose to take those animals off a truck, trying to get them to water in a strange place, then get them back on the truck.... It actually will be harming the animals more". 
The US abolition of horse slaughter was seen in a similar light:

110: "...down in the States where organizations like PETA and stuff have... convinced the government down there to not slaughter horses, animal welfare has definitely been compromised by that, being that now horses are not being fed because producers cannot afford to feed them and they're just letting them run free in the wild to be either starved to death or be killed by natural predators or have traffic on the highway hit them.... Maybe some people's hearts were in the right place but their minds weren't".

\section{Other values}

Beyond views about animal welfare, participants also provided insights into other values.

\section{Enjoyment/appreciation of animals}

In response to the question, "What do you enjoy about being a producer?" a majority of participants replied either "working with animals" or being "around cattle":

126: “... if you're involved in production, you're there for a reason because you like animals. There isn't anybody that works here that doesn't like animals because they could make a lot more money anywhere else.... It's because that's what they like to do".

182: "I really like working with cattle. Financially there's very little satisfaction, at the moment... It's almost therapeutic for me to go work cattle or move cattle".

134: "We just had two baby calves this morning. And I ... feel sorry for some of these people in the urban communities that can never appreciate the birth of a...little calf or anything, and appreciate it and then watch it grow".

Participants also described appreciating idiosyncrasies in their animals:

150: "You'll watch say ten cows come down to that [water] bowl. The boss cow gets to drink first. Of that ten, there'll be two that'll say, 'Ah, the hell with this', and they'll go down into the mud. Eight will say, 'We'll stand back and we'll wait - we'll wait here'. So, they're just like people. It's just fascinating for me to watch the comfort level of who they like to be with".

262: "We've hired some people that had no livestock experience whatsoever.... And once they start understanding cattle, they seem to have, you know, more respect for them, watching behaviour and understanding what some of these things that they're doing means".

\section{Lifestyle}

Many participants stressed that despite economic challenges they would continue raising cattle even in the event of a significant lottery win or major inheritance. Central to this decision was the enjoyment of the 'lifestyle' associated with ranching:

126: "You wouldn't be doing that for the money because there hasn't been enough money in agriculture to do it for the money. I don't think there are people in this business for the money. So what drives them then? It's the lifestyle. You're raising your kids on it. Well, what else is it? Well, it's looking after animals. That's why we're here". 
128: "We could all go work for wages on the oil industry for far more money than we are making now. And that's what it comes down to: we want to do this because we love the lifestyle...".

\section{Tradition}

While valuing the traditions of cattle ranching, participants showed no widespread resistance to replacing traditional methods with more modern approaches. In fact, proponents of low-stress handling occasionally pointed out that low-stress methods have always been part of the ranching tradition:

118: "You don't yell at cows unless you have to... that was a pat rule in 1890. If you were trailing cattle up here, and you yelled at a cow, you went and picked up your pay. They knew lots about handling cattle that most people now don't".

Some participants expressed support for 'branding parties' when ranchers would co-operate over branding and other management practices. One participant who expressed ambivalence over branding and recognised that technology would likely make branding obsolete, still noted:

134: “... It's going to be very tough, though, because that's how we've always done it. That's the West. Branding is just part of it".

Another participant explained that even some proponents of low-stress handling still attended traditional brandings because, "it's sort of like we're back in the old West".

\section{Beliefs about cattle as sources of food}

Several participants were also clear that they did not regard cattle as 'pets':

260: "We don't consider them pets. We know them... occasionally there's some that have names... but, they aren't pets... we have a different relationship with our horses, for sure, and with our dogs, for sure. But, the cattle, it's a business and they aren't pets".

146: "I don't have a relationship with them. You buy them, put them in, you feed them, and then you ship them. I certainly have to take care of them because if I don't they die, or they don't gain as well or anything else, so their needs have to be met, but as far as being pets, no".

Upon probing, participants often made reference to the role of 'growing up' on ranches or farms and participating in '4-H' programmes (see Discussion) which, among other activities, teach animal care and handling to rural children. Many believed that this helped ready them to understand, and eventually accept, the place of food animals:

260: "The very closest we get is with $4-\mathrm{H}$ animals... and that's where you really do your petting. You do your grooming and everything, and you go through the stresses of the animal parting. And, there's been tears shed, for sure, but everyone gets over it... they have to".

262: "I guess it's a lot easier for somebody that grew up on the farm and seen those things... where you raised livestock and you slaughtered them right on the farm, to put food in the freezer....You see that growing up; it's a lot easier".

Moreover, while participants obviously supported the rearing of food animals for human consumption and producer income, such support was contingent upon the provision of diligent care: 
182: "The livestock here are extremely well taken care of....but their end result is to feed me or other people and that's how we make a living".

156: "I had to explain this to a ten-year-old vegetarian girl. She said, 'Why, if you love animals, do you eat meat?' And I explained to her... 'My animals have a good life. They get to live like we could only dream. They don't have to work. They just eat, drink, raise their babies, hang out with their friends, and then one day, it's done.... We are thankful for them. We take good care of them. And that's why God put them on earth"'.

\section{Contributions to society}

Participants also emphasised the broader, social contributions that they made, especially as food producers:

112: "I'm a food producer for gosh sakes. It's the most essential thing. You can do without a car, a skidoo, a four-car garage, a swimming pool, a sauna! But you got to have food!"

116: "From my perspective animal production is production of food to sustain our population....food production is where I'm coming from".

Some participants also stressed the contribution that ranching makes to the preservation of wildlife and the environment. One considered that, "large tracts of privately held land are the last great hope for wildlife", because parks are too heavily used by people for large predators to thrive. Another noted the importance of preventing manure from harming waterways. Another described his attempts to re-establish native wild grasses. Others saw their primary role as managing natural grasslands and regarded successful cattle production as a consequence of good grassland management.

\section{Discussion}

In this qualitative study, our goal was to capture the range of beliefs, values and attitudes on farm animal welfare among commercial ranchers and feedlot operators, and to provide insights, where possible, about the nature of those views. We found a wealth of perspectives, including some areas of agreement as well as some controversy.

Although participants reported not using the term 'animal welfare'-and were even wary of it as the language of their critics - the views they expressed represented a comprehensive grasp of animal welfare as it is commonly understood. Most expressions of concern about animal welfare fall into three main categories: biological functioning (satisfactory health, growth and normal functioning of physiological and behavioural systems); affective states (avoidance of pain and suffering, plus positive states such as comfort and contentment); and 'natural living' which is variously understood as the ability of animals: (i) to perform their natural behaviour; and (ii) to live in reasonably 'natural' environments (Fraser 2006). All of these concerns were clearly reflected in the views of participants, apart from a tendency to downplay short-term pain resulting from invasive procedures as discussed below.

An interview-based study of cattle producers (dairy, veal and beef) in six European countries (Kjaernes et al 2008) identified some clear similarities to, and differences from, our findings. Similar results include an emphasis on animal comfort (Kjaernes et al 2008; $p$ 296), on minimising stress (pp 300-301), on vigilant, non-artificial efforts to prevent disease in organic operations (pp 284-285), and on assessing animal welfare through animal health and physical appearance ( $p 300$ ). Moreover, as in our study, the act of ruminating was interpreted as a sign that animals are calm, peaceful and possessing good welfare (Kjaernes et al 2008; $p$ 300), and cattle were not regarded as pets ( $p$ 295). Overall, producers in both 
studies contextualised animal welfare within an overarching framework of 'good animal care, directly engendering good animal performance, directly facilitating positive economic returns' (Kjaernes et al 2008; p 258).

However, European producers, especially cow-calf or 'suckling cow' producers, although emphasising opportunities to express 'natural behaviour' (Kjaernes et al 2008; p 258), did not place the same emphasis on access to the outdoors that we found among Canadian producers. Although suckling cows in Europe are raised typically on pasture in summer, most are kept indoors in winter (at least partly to protect animals from winter rains) and many fattening cattle are reared indoors on grain-based diets (Kjaernes et al 2008). Given this tradition, European beef producers may be less likely to see cattle welfare as closely linked to outdoor environments. It is unclear to what extent producers in this study favoured outdoor environments because of personal values versus practical necessity. In any case, Canadian participants placed strong emphasis on protecting animals from extreme natural hardships by such means as wind-breaks and efforts to minimise calving complications, both directly through attending births, and more indirectly through the use of bulls apt to sire low-birth-weight calves resulting in easier calving.

Three other studies have focused specifically on beef producers. In terms of handling cattle, Boivin et al (2007) found that French producers recognised that animals were sensitive to shouting and responded well to human contact ( $p$ 148); however, one-fifth of producers considered cattle relatively insensitive to pain ( $p$ 148). Vanhonacker et al (2008) and Phillips et al (2009) found that beef producers from Belgium and Australia (respectively) seemed to accept the relatively short-term pain associated with invasive practices. Similarly, some participants in our study appeared to dismiss or de-emphasise pain associated with invasive management procedures. In some cases, participants expressed concern over such pain but saw painful practices as obligatory and beyond their control. Other participants tended to dismiss the pain as relatively unimportant. Still others tended to see such pain as an acceptable trade-off to prevent more serious problems such as injuries caused by intact horns or persistent mounting, aggression, and out-of-season calving caused by uncastrated bulls.

In an ethnographic study of Scottish beef industry workers, Wilkie (2005) examined the contradiction inherent in both providing care and producing 'sentient commodities' ( $p$ 213). Drawing on sociological theory, Wilkie discussed varying degrees of attachment and detachment in human-livestock interactions. She identified certain relationships as 'concerned attachment', for example, among breeders adopting a relatively humanised and individualised style of interaction with animals, whereas others were seen as displaying 'detached detachment', for example, among workers in slaughter plants where livestock are perceived more purely as commodities. In our study, many participants seemed to fall along a continuum of 'concerned detachment', with producers expressing concern for animals that stood out individually or during times of vulnerability such as calving, whereas other participants described relationships of a more detached nature.

In this study, overall, producers reflected a view of animal care centred on reducing 'stress'. Specifically, they saw stress as the antithesis of their goal of calm, contented animals resting, ruminating and making steady weight gains. Stress was not necessarily seen as intrinsically unacceptable. Specifically, stress that resulted from natural environments or that was deemed unavoidable was accepted generally, whereas stress was widely regarded as unacceptable where cattle were not treated according to basic standards of care. Such contextualising of stress would seem consistent with the need to balance tradeoffs and to manage within operational limits.

There was also a strong adherence to low-stress handling. In this vein, participants expressed concern over keeping these relatively flighty animals restrained any longer than necessary. As one participant 
suggested, this may help explain the lack of interest in local anaesthesia whose use would require longer handling times.

Participants in this study made frequent references to childhood experiences involving '4- $\mathrm{H}$ ' clubs (standing for Head, Heart, Hands and Health) suggesting that these longstanding programmes help to socialise ranch children into the world and values of beef production, including the rearing of cattle for sale and slaughter. Similarly, in an American study, Ellis and Irvine (2010) found that 4-H participants acquire several strategies for dealing with the emotional conflict over the rearing of animals and their eventual slaughter. These were: (i) 'cognitive emotion', or redefining feelings for animals to avoid developing attachment; (ii) 'distancing', or regarding livestock as 'market animals' bred and born exclusively for market purposes; and (iii) 'narrative redemption' associated, for example, with laudable plans for the money earned through sales as well as plans to replace current animals with others in a natural cycle of life (pp 27-32).

Perhaps in keeping with traditional 4- $\mathrm{H}$ training, there were also clear values associated with standards of animal care. Widely shared standards included concerns about overstocking pens, rough handling, and failure to maintain satisfactory handling facilities, to meet nutritional needs, and attend to sick or injured animals in a timely manner. And without directly criticising organic producers, non-organic producers also emphasised the need for basic health-care including vaccinations and therapeutic antibiotics. Taken together, these appeared to constitute a set of fundamental welfare standards shared by the participants.

Participants also had strong views on what they regarded as problems in the industry. Chief among these were Canadian trucking regulations that require offloading and reloading of cattle during long journeys (maximum legal transit time in Canada is $52 \mathrm{~h}$ ). Although trucking itself is usually regarded as stressful for animals, unloading and reloading at rest stops tended to be seen as unnecessarily stressful and the cause of unnecessary weight loss. Hence, producers would presumably welcome an assessment of federal transport policies and of factors that make long-distance transport necessary in Western Canada.

Participants were also critical of 'hobby farming' - a widespread practice in Canada (Boyd 1998) — specifically that hobbyists lack the requisite skills, knowledge, and appreciation of their role within the food production chain. In doing so, producers were perpetuating a tradition of criticism directed toward hobby farmers by advocates of commercial farming (eg Daniels 1986; Hart 1992). At the same time, Holloway (2001) outlined an often complex and varied depiction of hobby farmers' relationships with their livestock whereby animals were frequently reared and regarded more as pets or companions than resources for monetary gain. A systematic examination of professionalism and animal care among parttime producers would likely be welcomed by the Canadian beef industry.

There were areas of disagreement between producers within this study. Organic producers either directly or indirectly expressed welfare concerns over the practice of winter calving. This was not the case with non-organic producers. Hence, winter calving would be a suitable subject for further scientific review or study.

Furthermore, cow-calf producers in particular expressed a strong but variable sense of responsibility to provide care. Some reported being very self-sacrificing while others looked upon extreme personal efforts as 'spoiling' animals. Also there were clear differences in the extent to which producers either expressed concern about possible pain/distress inflicted on their animals or the degree to which they appeared to make efforts to limit pain. Hence, it is possible that operative definitions of 'comfort' or 'contentment' may vary. In some cases, both terms may be used synonymously with basic standards of care. In others, comfort or contentment may include practices that exceed basic standards. Alternatively, there may be a willingness among some producers to voluntarily surpass basic levels of care solely in accord with held 
values that may not be shared or expressed by others. It may also be, however, that some producers do not equate good welfare with making all possible or even feasible efforts to reduce pain or suffering. Enabling cattle to experience fully natural lives_including some hardships-may also be seen as providing opportunities to lead relatively authentic or meaningful lives.

A recurring theme was economics. On one hand, participants believed that thin profit margins had constrained the ability of some producers to improve shelter or handling facilities. On the other hand, producers indicated that their cattle were not subjected to poor welfare in order to reduce costs as such actions would eventually reduce revenues. In short, participants were decidedly satisfied with the level of care currently provided to their animals. However, most participants were willing to alter their rearing methods in order to accommodate perceived customer wishes provided that those wishes did not conflict with basic standards of animal care and that consumers were willing to pay. Hence, any prospective welfare-oriented amendments to current practices must take into account feasibility, cost efficiency and impact upon retail pricing. Most participants expressed a love of working with animals but virtually all insisted that their relationship with cattle was not like their relationships with horses or dogs. In contrast, relationships with cattle were more distant and removed. Other motivations for ranching included a preference for the relatively independent lifestyle, the preservation of tradition, opportunities to steward a natural environment, and the satisfaction associated with helping to feed others.

The picture of beef producers that arises in our study is quite unlike the views of animal producers fostered by some critics. As examples, Singer (1990) claimed that "the meat available from butchers and supermarkets comes from animals who were not treated with any real consideration at all while being reared" (1990), and Regan (2004) maintained, with regard to farm animals, that "pain and deprivation are heaped upon them in amounts beyond human calculation". In contrast, our participants, although clearly subject to economic constraints and motivations, uniformly expressed an ethic of care, strong interest in and enjoyment of animals, certain ethical standards and concerns, and varying degrees of willingness to sacrifice their own comfort for the sake of their animals.

Animal welfare implications

Public debates about the proper care and handling of food animals often fail to directly involve actual producers who play a vital role in implementing animal welfare practices. Giving voice to the beliefs and concerns of producers, as we have attempted to do in this study, could strengthen animal welfare policy by identifying topics that are likely to engage producers while identifying areas of broad social consensus as well as disagreement. Similarly, farm animal welfare advocacy may more successfully engage producers if criticisms acknowledge and address the range of animal welfare views held by producers.

\section{Acknowledgements}

Funding for this study was provided by the Social Sciences and Humanities Research Council of Canada (SSHRC) and the Animal Welfare Program and its donors. The authors are grateful for the helpful discussions and other contributions provided by the members of the Animal Welfare Program as well as by Drs Bettina Bock, Ian MacLachlan, David Mellor, Colin Morgan, Bailey Norwood, Kevin Stafford and Unni Kjaernes. Valuable support and contacts were provided by Drs Eugene Janzen, Douglas Veira, Karen Schwartzkopf-Genswein, and Dr Terry Church, Susan Church, Adele Buettner, Shanyn Silinski and Pam Heath. We also thank our anonymous reviewers for your valuable comments. A special thanks to all participants who cannot be named for reasons of confidentiality but whose openness and warm hospitality made the study an enjoyable as well as an informative experience. 


\section{References}

Adamson J, Gooberman-Hill R, Woolhead G and Donovan J 2004 'Questerviews': using questionnaires in qualitative interviews as a method of integrating qualitative and quantitative health services research. Journal of Health Services Research \& Policy 9: 139-145. http://dx.doi.org/10.1258/1355819041403268

Bock BB and van Huik MM 2007 Animal welfare: the attitudes and behaviour of European pig farmers. British Food Journal 109: 931-944. http://dx.doi.org/10.1108/00070700710835732

Boivin X, Marcantognini L, Boulesteix P, Godet J, Brule A and Veissier I 2007 Attitudes of farmers towards Limousin cattle and their handling. Animal Welfare 16: 147-151

Boyd S 1998 Hobby Farming: For Pleasure or Profit (Working Paper \#33). Ministry of Industry, Statistics Canada: Ottawa, Canada

Daniels TL 1986 Hobby farming in America: rural development or threat to commercial agriculture? Journal of Rural Studies 2: 31-40. http://dx.doi.org/10.1016/0743-0167(86)90071-9

Ellis C and Irvine L 2010 Reproducing dominion: emotional apprenticeship in the 4-H youth livestock program. Society and Animals 18: 21-39

Ellis KA, Billington K, McNeil B and McKeegan DEF 2009 Public opinion on UK milk marketing and dairy cow welfare. Animal Welfare 18: 267-282

Fraser D, Weary DM, Pajor EA and Milligan BN 1997 A scientific conception of animal welfare that reflects ethical concerns. Animal Welfare 6: 187-205

Fraser D 2006 Animal welfare assurance programs in food production: a framework for assessing the options. Animal Welfare 15: 93-104

Hammersley M and Atkinson P 2007 Ethnography: Principles in Practice, Third Edition. Routledge: London, UK

Hart JF 1992 Non-farm farms. Geographical Review 82: 166-179. http://dx.doi.org/10.2307/215430

Holloway L 2001 Pets and protein: placing domestic livestock on hobby-farms in England and Wales. Journal of Rural Studies 17: 293-307. http://dx.doi.org/10.1016/S0743-0167(00)00045-0

Kjærnes U, Bock B, Roe E and Roex J 2008 Consumption, distribution and production of farm animal welfare. Welfare Quality $\AA^{\circledR}$ Reports Cardiff University: Cardiff, UK

Lassen J, Sandøe P and Forkman B 2006 Happy pigs are dirty! - conflicting perspectives on animal welfare. Livestock Science 103: 221-230

Phillips CJC, Wojciechowska J, Meng J and Cross N 2009 Perceptions of the importance of different welfare issues in livestock production. Animal 3: 1152-1166. http://dx.doi.org/10.1017/S1751731109004479

Regan T 2004 Empty Cages: Facing the Challenge of Animal Rights. Rowman \& Littlefield: Lanham, USA Singer P 1990 Animal Liberation, Revised Edition. Avon Books: New York, USA 
te Velde H, Aarts N and van Woerkum C 2002 Dealing with ambivalence: farmers' and consumers' perceptions of animal welfare in livestock breeding. Journal of Agricultural and Environmental Ethics 15: 203-219. http://dx.doi.org/10.1023/A:1015012403331

Vanhonacker F, Verbeke W, Van Poucke E and Tuyttens FAM 2008 Do citizens and farmers interpret the concept of farm animal welfare differently? Livestock Science 116: 126-136. http://dx.doi.org/10.1016/j.livsci.2007.09.017

Wilkie R 2005 Sentient commodities and productive paradoxes: the ambiguous nature of human-livestock relations in northeast Scotland. Journal of Rural Studies 21: 213-230. http://dx.doi.org/10.1016/j.jrurstud.2004.10.002

Williams B 2011 Bud Williams Schools. Available at: http://stockmanship.com/. (Accessed November 2011) 